IZA DP No. 6078

Ethnic Identity and Immigrants' Wages in Greece

Nick Drydakis

October 2011

Forschungsinstitut zur Zukunft der Arbeit Institute for the Study of Labor 


\title{
Ethnic Identity and Immigrants' Wages in Greece
}

\author{
Nick Drydakis \\ University of Patras \\ and IZA
}

Discussion Paper No. 6078

October 2011

\author{
IZA \\ P.O. Box 7240 \\ 53072 Bonn \\ Germany \\ Phone: +49-228-3894-0 \\ Fax: +49-228-3894-180 \\ E-mail: iza@iza.org
}

\begin{abstract}
Any opinions expressed here are those of the author(s) and not those of IZA. Research published in this series may include views on policy, but the institute itself takes no institutional policy positions.

The Institute for the Study of Labor (IZA) in Bonn is a local and virtual international research center and a place of communication between science, politics and business. IZA is an independent nonprofit organization supported by Deutsche Post Foundation. The center is associated with the University of Bonn and offers a stimulating research environment through its international network, workshops and conferences, data service, project support, research visits and doctoral program. IZA engages in (i) original and internationally competitive research in all fields of labor economics, (ii) development of policy concepts, and (iii) dissemination of research results and concepts to the interested public.
\end{abstract}

IZA Discussion Papers often represent preliminary work and are circulated to encourage discussion. Citation of such a paper should account for its provisional character. A revised version may be available directly from the author. 
IZA Discussion Paper No. 6078

October 2011

\section{ABSTRACT \\ Ethnic Identity and Immigrants' Wages in Greece}

This study investigates the impact of ethnic identity on Albanian, Bulgarian, Romanian, Georgian, and Russian wages in Greece. Treating ethnic identity as a composite of language, cultural habits, ethnic-self identification, societal interaction, and future citizenship plans, the estimations suggest that assimilation and integration are positively associated with immigrant wages, while separation and marginalisation are negatively associated with immigrant wages, after considering various demographic and pre- and post-immigration characteristics. In addition, dramatic wage growth for fully assimilated and integrated immigrants, and vast wage losses for totally separated and marginalised immigrants are estimated. A healthy Greek - as well as a European - immigration system should recognise labour immigration flows and the potential of repeat immigration and evaluate the cornerstone features of ethnic identity.

JEL Classification: F22, J15, J16, Z10

Keywords: ethnic identity, earnings

Corresponding author:

Nick Drydakis

Department of Economics

University of Patras

University Campus

26504 Rio

Greece

E-mail: ndrydakis@econ.soc.uoc.gr 


\section{Study's aim, theoretical framework and hypotheses}

During the course of immigration the concept of ethnic identity becomes particularly meaningful ${ }^{\mathrm{i}}$ given that there is a sufficient cultural distance between the home and the host country. A few studies investigate what happens to immigrants who have developed in one cultural context and attempt to re-establish their lives in another (Berry, 1980; 1997; Phinney et al, 2001). The choice of immigrants to be specific types of people becomes, then, a powerful decision with substantial socio-economic consequences for both the individuals and the host country (Phinney et al, 2001). Indeed, research suggests that it is ethnic identity rather than the ethnicity of immigrants that defines their economic behaviour (Mason, 2004; Ogden et al, 2004; Laroche et al, 2005; Constant and Zimmermann, 2008; Algan et al, 2010). The balance of cultural attachments probably positively affects immigrants' income which corresponds to economic success in the host country, through consumption, saving and investments increasing (Chiswick 1978; 1997; 1998; Constant and Zimmermann. 2008). Actually, it is suggested that, the more successful immigrants are in labour market, the higher their net economic and fiscal contribution to the host economy will be (Algan et al, 2010). On the other hand, studies suggest that ethnic identity affects behaviour in a way that is detrimental to the labour market in the host country (Akerlof and Kranton, 2000). Unemployed immigrants living in poverty are a source of problems because national spending (benefits) to support them grows, urban areas become stigmatised, and criminality increases (Cutler, 1997; Oreopoulos, 2003; Fairchild, 2009; Battu and Zenou, 2010; Dancygier, 2010; Dickerson and Johnson, 2010; Xie, 2010). As a result, the ways that immigrants adapt to differences between the cultures of the original 
country and host country are of great interest, and supports general cross-country predictions as a factor on individual well-being and institutional design.

The current study investigates how various forms of immigrant adaptation with respect to the cultures of the origin and Greece affect immigrants' wages. The cultural diversity in Greece is increasing rapidly. Because Greece is so culturally diverse, many people are immigrants, have immigrant parents, or have immigrant classmates or neighbours. Faced with growing inflows of immigration from countries with different ethnic and cultural compositions, ethnic identity has become a recent addition to the Greek public debate on immigration (Balourdos, 2010). The Prime Minister, in a 2010 speech to parliament emphasises: 'You are born Greek, and you can become Greek'. As a result, Greece approved an examination that requires knowledge in written Greek, Greek history, and Greek political/cultural values for legal immigrants who have been in the host country for five years and are seeking Greek citizenship (Ministry of Interior-Law 2010/3833) ${ }^{\mathrm{ii}}$.

Actually, the collapse of the communist regimes at the end of the 1980s caused an unprecedented influx of economic immigrants, mainly from the former communist countries of Eastern Europe and the Soviet Union, into Greece. The inflow of migrants reached its peak at the beginning of the 1990s, when Albanians started moving into Greece $^{\mathrm{iii}}$. Recent estimates that take into account undocumented immigrants raise the total number of immigrants in the early years of the twenty-first century to more than one million, i.e., 10\% of the Greek population (Gropas and Triandafyllidou, 2005; Kontis et al, 2006; Maroukis and Triandafyllidou, 2008; Balourdos, 2010). According to the most relevant census (2001), immigrants from Albania account for more than half of all immigrants $(57.5 \%)$. The second largest group consists of those from Bulgaria 
(4.6\%), followed by immigrants from Georgia (3.0\%), Romania (2.9\%), and Russia $(2.3 \%)^{\mathrm{iv}}$. The multicultural environment in Greece creates many opportunities for international interactions ${ }^{\mathrm{v}}$, and given the increasing diversity, the concept of ethnic identity has become increasingly important. And, as Greece is experiencing immigration for the first time in historical memory, it is critically important to know how immigrants perform in the labour market and affect society ${ }^{\mathrm{vi}}$.

In spite of the interest in ethnicity and discrimination in the Greek labour and housing market (Drydakis and Vlassis, 2010; Drydakis, 2010a; Drydakis, 2011) ethnic identity and economic outcomes have not been subject to examination. This study extends previous work by explicitly accounting for ethnic identity patterns by utilizing the Greek Migration Study (2009-2010), which deliberately samples the five most overrepresented immigrant groups in Greece (Albanians, Bulgarians, Romanians, Georgians, and Russians) and contains information on various issues surrounding ethnic identity. Berry's model $(1980 ; 1997)$ is a useful theoretical framework for understanding variations in ethnic identity. The earlier study suggests that commitments to two different societies can coexist and influence each other in several ways. Berry uses two questions as a means of identifying strategies adopted by immigrants to deal with the movement between country-of-origin and host country cultures: 1) is maintaining one's cultural heritage considered valuable? and 2) is it considered important to develop relationships with the larger society? According to Berry (1980; 1997), four patterns that result from variations of ethnic identities can be derived from a combination of answers to these questions. An immigrant who identifies strongly with the new culture, coupled with a weak identification to the origin culture has an assimilated identity, whereas an immigrant who combines strong identification with the 
host country culture and strong identification with the culture of origin is considered to have an integrated identity. An immigrant who has an exclusive commitment to the original culture paired with weak involvement with host country culture has a separated identity, and finally, an immigrant who has a weak dedication to or a strong detachment from the host or origin culture has a marginalised identity ${ }^{v i i}$. Similar to Berry (1980; 1997), Montgomery (1992), Unger et al (2002), and Nguyen and von Eye (2002), in this study there is recognition that maintaining or losing one's own culture and selfidentification with a place of origin is very closely related to gaining the culture of and self-identifying with the host society. Moreover, the current study assumes that attachments to any culture are not only about language and self-identification but rather a combination of these and other factors. Immigrants' ethnic identities are measured as a composite of several observable elements-including language, cultural habits, ethnicself identification, societal interaction, and future citizenship plans-to construct, as in Berry (1980; 1997) and Constant and Zimmermann (2008), indexes that measure the four possible ethnic identity patterns.

In the literature, there is evidence that assimilation entails advantages in the labour market (Izquierdo et al, 2009; Battu and Zenou, 2010; Casey and Dustmann, 2010). The consensus is that immigrants entering the host country are at large disadvantage mainly because they lack the necessary skills and human capital required in the receiving labour market. Even when immigrants possess this capital, it is not always possible to have it recognised by the host country, rendering them officially unskilled. The classical assimilation approach suggests that with time spent in the country, immigrants become more like natives because they are exposed to the new society and are investing in local human and social capital (Borjas, 1985). An 
acquisition of host country language skills and cultural understanding and knowledge is likely to provide employment opportunities and productivity, social networks, access to information and the knowledge required to succeed in the host country. Therefore, labour market disparities between comparable immigrants and natives decrease and may even virtually disappear (Chiswick et al, 1997; Berry, 1997; 2006; Izquierdo et al, 2009). However, studies on bicultural identities (i.e. integration) suggest that maintaining a commitment to the culture of origin after immigration can be beneficial because it provides immigrants with valuable ethnic-specific capital. Integrated immigrants may have greater employment advantages in the labour market, due to higher human capital (knowledge of two languages), possession of ethnic capital, and access to two ethnic networks (Berry, 1997; Constant and Zimmermann, 2008; Constant et al, 2009a). Thus, the first hypotheses related to ethnic identity patterns and immigrants' wages are the following:

Hypothesis 1: Assimilation is likely to provide positive wage returns to immigrants, due to adoption of the Greek language, cultural habits, ethnic-self identification etc.

Hypothesis 2: Integration is likely to provide even greater wage returns to immigrants, compared to assimilation, as knowledge of two languages, access to two distinct cultural networks, etc., further rises wage opportunities in Greece.

In addition, several scholar studies suggest that separation, although it may stem from discrimination or a desire to display greater ethnic solidarity, entails a lack of investments in specific human and social capital required in the host labour market. 
Isolation from the host country's culture may lead immigrants not to participate in social activities that help to develop network structures supportive of labour market success (Akerlof and Kranton, 2000; Selod and Zenou, 2006; Constant and Zimmermann, 2008; Battu and Zenou; 2010). Furthermore, studies evaluate that marginalisation involves rejection by the dominant society combined with a country-oforigin culture loss which entails the presence of hostility and much reduced social support (Berry and Sam, 1997; Battu and Zenou, 2010). Actually, immigrants that have preferences that accord with being oppositional do experience extensive employment penalties (Battu and Zenou, 2010) ${ }^{\text {viii }}$. The knowledge of the host language and the acquisition of basic skills are essential for immigrants, as without them, many immigrants find it difficult to enter the official labour market, and as a result many remain at the margins of society long after they have moved into the country (Borjas, 1985; Berry and Sam, 1997; Chiswick et al, 1997; Battu and Zenou, 2010; Casey and Dustmann, 2010). Thus, the second hypotheses related to ethnic identity and immigrants' wages are the following:

Hypothesis 3: Separation cannot be wage beneficial because it provides immigrants with inadequate human capital (i.e. language, cultural networks, etc) required in Greece.

Hypothesis 4: Marginalisation is likely to result in even higher wage losses, compared to separation, in Greece due to immigrants' isolation from two distinct languages, cultural networks, cultural habits etc. 
Thus, the main question under examination is whether an immigrant who is culturally well adjusted to the host society is likely to receive higher wages than an immigrant who retains a stronger affiliation with her or his own culture? The study's estimations will conclude that assimilation and integration are positively associated with wages. Assimilation, however, provides higher wage returns to immigrants than integration. Thus, we accept Hypothesis 1 and we reject Hypothesis 2. On the other hand, separation is negatively associated with immigrant wages. Thus, we accept Hypotheses 3. Marginalization, however, is associated with higher wage losses than separation thus we accept Hypotheses 4. Meanwhile, the results will indicate dramatic wage growth for fully assimilated and integrated immigrants and vast wage losses for totally separated and marginalised immigrants. In addition, an in-depth evaluation of each group will serve to illuminate the study's hypotheses and outcomes and will provide valuable information.

Although there are differences depending on how one measures ethnic identity, and each country does have a very different immigration policy, this paper also finds evidence of a positive association between labour market outcomes and host country identity. Thus, the current paper adds to the limited European studies mainly from Spain (Izquierdo et al, 2009), England (Battu and Zenou, 2010), and Germany (Constant and Zimmermann, 2008; Casey and Dustmann, 2010) that evaluate positive relationships between immigrants' identification with a host country and their economic outcomes. The rest of the study is organized in five sections. Section 2 evaluates how the Greek Migration Study classifies ethnic identity. Section 3 analyses the data set, and Section 4 presents the descriptive statistics, and the estimation results. Section 5 is a summary and conclusion. 


\section{Measuring ethnic identity}

While a general understanding of flexible ethnic identity is shared among many social scientists, there is still no consensus on all of the specific elements that compose ethnic identity. Among the suggested and widely used key elements of ethnic identity are the subjective expression of one's commitment to, sense of belonging to, or selfidentification with the culture, values, and beliefs of a specific ethnic group and social life (Unger et al, 2002). Many short scales have measured language usage as a proxy for ethnic identity because language fluency affects a person's ability to communicate both with members of the host culture and with members of the culture of origin (Epstein et al, 1998). However, language usage is not the only important component of ethnic identity. Contact with another culture and the attempt to coexist with people from another culture can cause individuals to change their attitudes, beliefs and customs, choice of foods and entertainment. Thus, the cultural elements most frequently employed in ethnic identity studies are language, media, food preferences, and societal interaction (Unger et al, 2002; Laroche et al, 2005). A combination of these elements has been used to develop measurements of ethnic identity that are either specific to a certain ethnic group of individuals (Nguyen and von Eye, 2002) or are generally applicable to ethnically diverse samples of immigrants (Phinney,1992; Laroche et al, 2005).

The Greek Migration Study, by combining information on [A] language, [B] cultural habits (food, media, music and reading), [C] self-identification, [D] societal interaction, and [E] future citizenship plans, offers the chance to construct a most informative measure of ethnic identity. In actuality, the Greek Migration Study, being influenced by the international bibliography (Berry and Sam, 1997; Constant and 
Zimmermann, 2008), identified direct questions regarding immigrants' personal devotion to Greek culture and society with the commitment to the culture and people of their origin, to generate the four variables: assimilation (AS), integration (IN), separation (SE), and marginalisation (MA). Table 1 presents the relevant questions and the options. Immigrants had to evaluate the ethnic identity patterns of the five cultural elements by choosing among the four alternative scenarios to best describe their commitments. For instance, to evaluate whether immigrants were assimilated, integrated, separated or marginalised concerning language usage, respondents had to choose which of the following options described their situation the best: (1) a strong identification with the Greek language, coupled with a weak identification with the language of origin, (2) combination of strong identification with the Greek language and strong identification with the language of origin, (3) an exclusive commitment to the language of origin, paired with weak involvement with the Greek language, (4) a weak dedication to or strong detachment from either Greek or the original language.

\section{[Table 1]}

The four scale scores were calculated by summing the responses within each category. Taking into account the five questions ([A], $[\mathrm{B}],[\mathrm{C}],[\mathrm{D}]$, and $[\mathrm{E}])$, the assimilation variable could equal to $x$ if the options that correspond to assimilation were chosen $x$ times. The same holds for integration, separation and marginalisation. For example, if individual i chooses the assimilation option twice and the integration option three times, among the five ethnic elements, then the assimilation variable for individual i equals two, the integration variable equals three, the separation variable equals zero, and the marginalisation variable equal zero. Thus, each variable can take a value between zero and five and add up to five for each individual. An individual who scores 
one in integration, zero in assimilation, four in separation, and zero in marginalisation, has a clear preference. An immigrant who scores two in integration, one in assimilation, two in separation, and zero in marginalisation, does not have a clear preference in his or her socio-cultural commitment.

Classifying immigrants as strictly integrated, assimilated, separated or marginalised in all five components can be misleading. A person can be culturally and linguistically integrated into the Greek society but still might have no friends in Greece or might strongly identify with the home country. This classification procedure suggests that it is practically impossible to determine the overall balance of migrants' commitments. In fact, in this sample, the context of the respondents' ethnic identities varies across the factor groups, which is why the measure is scientifically valuable. With this technique, it is also possible to discuss the status of ethnic identity in comparative terms. For example, if respondent one is identified as integrated in terms of language, culture, and self-identification and respondent two is identified as integrated only in terms of self-identification, then respondent one is generally more integrated than respondent two. If, on the other hand, respondent two is identified as separated in more factor groups than respondent one, he or she could be considered as more separated than respondent one. Finally, one could wonder to what extent the Berry indexes $(1980 ; 1997)$ differ from a direct measure of ethnic self-identification. Berry’s (1980; 1997) scale gives equal weight to each of the five aspects of ethnic identity, including the direct measure of ethnic self-identification, and allows for potential differences in four dimensions rather than just self-evaluation alone. As Constant and Zimmermann (2008) suggest, this methodology balances the responses by more 
objective 'indirect' measures of ethnic identity, as opposed to the self-identification question, which is subjective and open to debate.

\section{Data set}

Data were gathered from February 2009 to July 2010 in the Greek Migration Study, which was conducted by the University of Piraeus, the University of Central Greece, and Panteion University of Social and Political Sciences. The Greek Migration Study is one component of the multi-country study of the Scientific Centre for the Study of Discrimination (Intra-University Centre), which has collected information on the five biggest immigrant groups in Greece: Albanians, Bulgarians, Georgians, Romanians and Russians. The 2009-2010 Greek Migration Study consisted of written surveys. Male and female immigrants were invited to provide information relating to a variety of demographic and other characteristics. The study was conducted on large pools of immigrants (immigrants' centres and institutions; governmental and non-governmental organisations that deal with immigrants; antiracism centres) in the six largest (more than 100,000 population) cities in Greece (Athens, Thessaloniki, Patra, Iraklio, Larisa, Volos), in which immigrants are most heavily concentrated (Census, 2001). By the end of the data-gathering period (18 months), questionnaires had been delivered to each official body affiliated with the six towns. A letter from the Greek Migration Study committee was sent to each body and invited immigrants to participate in the intrauniversity survey of their attitudes and beliefs about their identity. Individuals were informed that their participation would be voluntary and that their data would be confidential. To participate, respondents were instructed to take the survey home and 
return the assent form to the secretariat of each body. The reply forms were returned then to the Greek Migration Study committee.

In this study, the sample was restricted to individuals aged 18-65 (the upper limit corresponding to the official retirement age in Greece), whose nationality is not Greek, who were not born in Greece, and who were not in school at the time of the survey (see also, Constant and Zimmermann, 2008; Casey and Dustmann, 2010; Manning and Roy, 2010). Immigrants had to evaluate their ethnic identity according to the five elements by replying to the questionnaire, as analysed and presented in Table 1. The data-gathering process generated samples of a typical validated size of 1,837 immigrants. This high degree of participation, which leads to many observations, can be attributed to several factors. The Greek Migration Study was an intra-university effort to examine issues critical to migrants, and there was excellent collaboration between the directors and secretaries of various organisations. Additionally, the gathering phase lasted several months, the questions were carefully designed, the anonymity of respondents was stressed and assured, and the questionnaires were dropped off and picked up at an agreed time by people (directors and secretaries) who were known in each body. Each of these factors thereby maximized the response rate and reduced any potential source of bias.

Respondents were asked to fill in three separate questions: whether they were employed (EM), whether they were unemployed (UN), and whether or not they were participants (NP) in the labour force. The Greek Migration Study constructed an hourly wage measure by dividing the last month's wages by self-reported working hours per month. Surveyors asked, 'What is your best estimate of your wage last month before 
taxes and other deductions?' The wage variable was defined as the natural logarithm of hourly earnings (HW).

There are numerous factors in addition to ethnic identity that could influence wage levels. To isolate the effect of ethnic identity on wages, we must appropriately control for all other factors that affect wages and that correlate with ethnic identity. Some of these factors pertain to individual productivity. The productivity variables used in this study are age, education, health status, and occupation. Moreover, information regarding pre- and post-immigration characteristics was also incorporated due to the high relevance of these characteristics to wage levels (Chiswick 1978; Chiswick and Miller, 1998; Constant and Zimmermann, 2008). The variable AGE measured the individual's age in years. To account for the fact that the influence of ethnic identity may differ by sex, a dummy variable for sex is included (SEX). The variable MARR was set to 1 if the respondent was married and to 0 otherwise. The variable CHIL measured the number of children in the household.

The country-of-origin dummies- Albanians (ALB), Bulgarians (BUL), Georgians (GEO), Romanians (ROM), Russians (RUS) - are assumed to account for all social, cultural and economic differences between immigrants due to their origin. To capture the possible effects of disability and disease ${ }^{\mathrm{ix}}$, the variable DIS was set to 1 if the individual's activities were limited by poor health and to 0 otherwise. To be comparable to previous research, we defined health status using the self-reported response to the question concerning conditions that limited the individual's ability to work (Baldwin and Johnson, 2000). For convenience, the variable definitions are summarised in the Table 2.

[Table 2] 
Further, the number of years since immigration to Greece (MIG) was also included, and a dummy for religious background was added to account for the fact that religious affiliation may have cultural effects distinct from those related to the country of origin. Thus, the variable CHR was set to 1 if the individual was Christian and to 0 otherwise $^{\mathrm{x}}$.

Further, the variable SCHOL was set to 1 if the respondent had completed the minimum mandatory education level and to 0 otherwise. The variable GRAD was set to 1 if the respondent had graduated from high school and to 0 otherwise. The variable UNIV was set to 1 if the respondent had a university or technical school diploma and to 0 otherwise. In this stage, whether or not education was received in immigrants' home countries was also controlled for. Thus, the variable SCHOLH was set to 1 if the respondent had completed the minimum mandatory education level in a home country and to 0 in all other cases. The variable GRADH was set to 1 if the respondent had graduated from high school in a home country and to 0 in all other cases. The variable UNIVH was set to 1 if the respondent had a university or technical school diploma from a home country and to 0 in all other cases. In addition, the variable PC was set to 1 if the individual had computer skills and to 0 otherwise. The variable ENGL was set to 1 if the respondent had knowledge of English and to 0 otherwise. The variable EXPER measured the individual's years of actual working experience. The variable EXPERH measured the individual's years of actual working experience in a home country. The variable EXPERG measured the individual's years of actual working experience in Greece.

The variable WHITE was set to one if the individual's occupation was considered white collar, and zero otherwise. Similarly, the variable BLUE was set to 
one if the individual's occupation was considered blue collar and zero otherwise. In addition the variable SERV was set to one if the individual's occupation was considered a service occupation, and zero otherwise. For greater occupational control, an additional variable was considered. The variable PUBL was set to one if the worker was employed in the public sector and zero if the employee was employed in the private sector (PRIV). In addition, the variable PART was set to 1 if the individual was a part-time worker and to 0 if the worker was a full-time worker (for Greece, this means eight hours per day). Finally, dummy variables indicating city locations were also included to control for potential effects.

\section{Analysis}

\section{4a. Descriptive statistics}

Table 3 shows the descriptive statistics, and this section offers a brief discussion. As observed in the Greek Migration Study, the non-participants are on the order of $22.5 \%$ (where the vast majority is women $93.7 \%$ ). The labour force consists of $85.3 \%$ employed and $14.6 \%$ unemployed. The majority of employed are men (59.8\%), whereas the majority of unemployed are women $(62.1 \%)$. The sample consists of $36.1 \%$ Albanians, $12.5 \%$ Bulgarians, $12.2 \%$ Georgians, $18.6 \%$ Romanians, and $20.4 \%$ Russians. The hourly wage rate is 4.1 Euros $^{\mathrm{xi}}$. For a better evaluation, it is observed that the blue-collar jobs constitute the lowest-paid occupations, followed by service jobs and white-collar jobs. Furthermore, between public and private sectors, the latter is the lower paid. Those immigrants in white-collar occupations and in the public sector earn the highest wages in the Greek Migration Study sample ${ }^{x i i}$. 
The results indicate that immigrants' average age is 36.9 , that they have 15.4 years of time living in Greece, and that they have 14.4 years of actual work experience in the host country. As regards education levels, $75.5 \%$ of the immigrants have completed the minimum mandatory education; $64.4 \%$ have a high school diploma; and $17.2 \%$ have a university or technical school degree. An important distinction of immigrants is the occupational category. Immigrants are less likely to be employed in white-collar jobs (3.3\%) and service occupations (24.4\%); they are overrepresented in blue-collar jobs (72.3\%). Moreover, a small number of immigrants are employed in the public sector $(7.0 \%)$. Notably, given the absence of census data, it is virtually impossible to test whether this sample is truly representative. However, this issue has been addressed by comparing the Greek Migration Study's descriptive statistics with those of a most recent study made by Demousis et al (2010), which uses a random sample, the Greek Household Budget Survey of 2005. A comparison of the two data sets reveals similar average ages of the respondents, gender division of immigrants, wage rates, and participation in occupations and sectors. This comparison suggests that the Greek Migration Study survey is, to a large extent, representative of immigrants in Greece.

\section{[Table 3]}

As for the ethnic identity variations, the largest portion of the immigrants is classified as separated (1.9), followed by those measured to be integrated (1.4), assimilated (1.1) and marginalised ${ }^{\mathrm{xiii}}(0.5)$. Thus, immigrants identify most with the culture of the home country. The same pattern is observed by Constant and Zimmerman (2008). However, one could suggest that by combining the assimilation and integration indexes, as long as both evidence value placed on the host country's identity, most 
immigrants can be found to identify with the host culture while adapting to the new culture. These measures reveal that the way that immigrants identify themselves cannot be restricted to two options - specifically, 'host ethnic identification' or 'home ethnic identification'-because several options and patterns elude these too-simple classifications and thus threaten the loss of valuable relationships and information. Accordingly, the assigned measurements suggest the validity of the Berry $(1980 ; 1997)$ indexes. The measurements suggest that commitments to two different societies can coexist.

An econometric analysis that takes all of these variables into consideration is necessary now to determine each identity pattern's impact on immigrants' wage levels.

\section{4b. Wage regression results and discussion}

We now investigate whether and to what extent commitment to the home country and/or to Greece is related to wages. The empirical work is based on the standard human-capital wage equation developed by Mincer (1974). The estimations are developed by systematically modifying the Mincer equation, as outlined in ethnic studies by Chiswick (1978) and Borjas et al (1992) and updated in an ethnic study by Izquierdo et al (2009) and in ethnic identity studies by Constant and Zimmermann (2008), Casey and Dustmann (2010) and Algan et al (2010). The wage equation, written below, relates the calculated wages to dummy variables for the demographic and control variables. The natural logarithm of the wage variable is used, and increases the efficiency of estimation because it increases the extent to which the variable approximates a Gaussian distribution. Equation (1) presents a linearly estimable specification of this basic model: 
$\ln \mathrm{W}_{\mathrm{i}}=\beta_{1} \mathrm{~A}_{\mathrm{i}}+\gamma_{1} \mathrm{I}_{\mathrm{i}}+\delta_{1} \mathrm{~S}_{\mathrm{i}}+\kappa_{1} \mathrm{M}_{\mathrm{i}}+\tau_{1} \mathrm{X}_{\mathrm{i}}+\varepsilon_{1 \mathrm{i}} \quad$ Equation (1),

where $\mathrm{W}_{\mathrm{i}}$ is the hourly wage of individual $i$; $\mathrm{A}_{\mathrm{i}}$ is the assimilation variable of individual $\mathrm{i}$; $\mathrm{I}_{\mathrm{i}}$ is the integration variable of individual $i ; S_{i}$ is the separation variable of individual $\mathrm{i}$; $\mathrm{M}_{\mathrm{i}}$ is the marginalisation variable of individual $\mathrm{i} ; \mathrm{X}_{\mathrm{i}}$ is a vector of pre-migration and post-migration characteristics that describe individuals and are thought to be related to wages; $\beta_{1}, \gamma_{1}, \delta_{1}, \kappa_{1}, \tau_{1}$ are the parameters to be estimated by the OLS model; and $\varepsilon_{1 \mathrm{i}}$ is the error term. The key variables of interest are the variables indicating ethnic identity. Statistically significant positive (negative) coefficients of assimilation/integration/separation/marginalisation would result in higher (lower) wages.

Notably, the aforementioned studies do not deal with sample selection issues. In the current paper, it is argued that participating and employed individuals may be nonrandom samples (Heckman 1974), and thus, efforts should be made to control for selfselection, modelling participation and employment simultaneously. We follow a recent study by Aldashev et al (2009), and we estimate statistically insignificant correlation between the errors of the participation equation and employment equation. Moreover, the controls for sample selectivity turned out to be statistically insignificant. As long as sample selection is not an issue under the current framework (the same pattern holds in Aldashev et al, 2009), the analysis that follows relies on Equation (1) and is comparable with the estimation frameworks of Constant and Zimmermann (2008), Casey and Dustmann (2010), and Algan et al (2010) ${ }^{\mathrm{xiv}}$. In addition, Hausman Endogeneity Tests (1978; 2001) are employed to test whether assimilation, integration, separation and 
marginalization are endogenous in this step. Higher wages may lead to assimilation or integration. On the other hand, lower wages may lead to separation or marginalization. All attempts brought no indications of endogeneity, rendering the framework appropriate $^{\mathrm{xv}}$. However, before we present our results, it is important to note that our estimates are associations and should not be interpreted in a causal way ${ }^{\mathrm{xvi}}$.

The wage regression results are found in Table 4. Assimilation and integration are positively associated with wages, however, assimilation provides higher wage returns to immigrants than integration, thus we accept Hypothesis 1 and we reject Hypothesis 2. On the other hand, separation is negatively associated with immigrant wages. Thus, we accept Hypotheses 3. Marginalization, however, is associated with higher wage losses than separation thus we accept Hypotheses 4. Although there are differences depending on how one measures ethnic identity and each country has a very different immigration policy, Constant and Zimmermann (2008) and Casey and Dustmann (2010) find evidence of a positive association between immigrant wages and the German identity. Moreover, for Spain, Izquierdo et al (2009) show that as time goes on, immigrants' human capital gains within the firm contribute to assimilation processes and reduce the wage gap relative to natives.

With respect to other variables of interest, results in the wage regression stage are as expected. Age, and years since immigration all have positive effects on wages. Actual work experience has a positive correlation with wages, and each education variable is positive as well. Moreover, those immigrants with a university or technical school diploma from their home countries also receive higher wages. In addition, wages negatively correlate with disability status. Concerning the occupation covariates, those in white-collar jobs receive higher wages, whereas those in blue-collar jobs receive 
lower wages. Furthermore, the effect on wages of having a public job is positive, as is having a full-time job. In Table 5, we perform separate regressions for each ethnic group to have a complete picture. In all cases, it is observed that immigrants who have greater identification with Greece receive higher wages, and those being marginalised receive lower wages. Moreover, we observe for each group the relations between wage and pre- and post-immigration characteristics, which are as expected. Note however that, to understand acculturation, one must understand also the interactional context in which it occurs. This includes the characteristics of the migrants themselves, the groups or countries from which they originate, their socioeconomic status and resources, the country and local community in which they settle, and their fluency in the language of the country of settlement (Schwartz et al, 2010).

\section{[Table 4]}

\section{[Table 5]}

Not also that, we can relax the assumption of equal weights in the constructions of the composite ethnic identity variables, to determine them empirically. Instead of assimilation, integration, separation and marginalisation composite variables, we enter each of the five attributes of the ethnic identity measure separately for assimilation, integration, separation and marginalisation. Similar to Constant et al (2009b) the explanatory value of the model is unchanged because the Adj. $\mathrm{R}^{2}$ has hardly improved (0.658) and the coefficients and significance levels of the rest of the regressors are also similar to the basic specification. The assumption of equal weights for the attributes of the ethnic identity is not rejected by the Wald-test statistic. Thus, there is an efficiency gain in imposing equal weight restriction and estimating the model parsimoniously. As in the basic specification, all estimated effect parameters for assimilation and integration 
across the five attributes are substantially larger in size than those for marginalisation and separation, again confirming the tendency of the suggested composite ethnic identity measures. Meanwhile, assimilation measurements still have advantages as compared to integration.

Having estimated the regression coefficients, it is interesting now to estimate the actual effect of ethnic identity patterns on hourly wages. In Table 6, following Casey's and Dustman's (2010) simulations, the points estimate suggests that a one-standard deviation increase of assimilation is associated with an increase in hourly wage rate of 19.1\%. Similarly, a one-standard deviation increase of integration is associated with an $8.7 \%$ increase in hourly wage. Conversely, a one-standard deviation increase of separation is associated with a decrease in hourly wage of $18.8 \%$. A negative effect is also estimated for marginalisation. That is, a one-standard deviation increase of marginalisation is associated with an increase in hourly wage rate of $15.7 \%$. For completeness, in Table 6, we offer all the variations across each and every ethnic group. In all cases, there is an advantage of assimilation/integration above separation and marginalisation.

\section{[Table 6]}

It is of further interest to conduct the Constant and Zimmermann (2008) simulations on the raw aggregate monthly wage and estimate the increase and decrease in immigrant wage in the cases of full integration, assimilation, separation and marginalisation. Each simulation should be understood as a change in the variable if the referenced measure of ethnic identity were at a maximum (equal to five) and the remaining three measures were at a minimum (equal to zero). Simulations are the log differences of earnings of the hypothetical average individual in full absorption and the 
average individual in the sample, evaluated as sample means for all variables. As shown in Table 7, if immigrants were fully assimilated, their monthly earnings would grow by $119.1 \%$, and if they were fully integrated, their monthly earnings would grow dramatically by $108.7 \%$. In this study, there is an advantage of assimilation above integration. Constant and Zimmermann (2008) found an increase in monthly earnings on the order of $157 \%$ for those immigrants being totally integrated and an increase in monthly earnings on the order of $119 \%$ for those immigrants being totally assimilated. Moreover, in the current study a full separation would lead to an $81.1 \%$ reduction in monthly earnings, and a full marginalisation would decrease the average monthly earnings by $84.2 \%$. Thus, there is a greater disadvantage of marginalisation in comparison with separation. Similarly, in Constant and Zimmermann (2008), a full separation classification would result in a $75.5 \%$ reduction in monthly earnings, whereas a full marginalisation would result in a $92.2 \%$ reduction in monthly earnings. In Table 7, we also offer simulations for each ethnic group. The group that will benefit the most from assimilation is Georgian workers, which constitute the most recently arrived immigrant group in Greece (among the five groups under examination). As we previously discussed, the assimilation theory evaluates that with time spent in the country, immigrants become more like natives because they are exposed to the new society and are investing in local human and social capital (Borjas, 1985). In addition, it seems in the current study that being bicultural (i.e. integrate) does not entail a higher advantage in the labour market, despite the likely knowledge of two languages, possession of ethnic capital, and access to two ethnic networks. It seems that the formal institutions of the labour market remain the province of the Greek language and culture 
and are hence more accessible to people with an understanding and knowledge of the Greek language and culture, regardless of the individual's additional ethnic capital.

\section{[Table 7]}

There are a number of practically important reasons why the assimilation and integration of immigrants matters, in addition to their contribution to higher wages, savings, investments and money transferred to their home countries. Assimilated and integrated immigrants may be important for the attitudes of the native population toward immigrants and, therefore, may also have an impact on immigration policy (see Algan et al, 2010). Thus, if cultural diversity has attendant costs and benefits, the public needs to take account of them. This might involve new immigration policies (regarding, e.g., how many immigrants or what kind of immigrants — skilled/unskilled, highly/lowly educated, from which countries-to allow $i^{\text {xvii }}$ ) or policy on the assimilation/integration of immigrants once they are in the country, e.g., forcing them to learn the language or to take exams for citizenship. As Massey and Denton (1993) suggest, segregation creates the structural conditions for the emergence of an oppositional culture that devalues work, schooling, and marriage and stresses attitudes and behaviours that are antithetical and often hostile to success in the larger economy. Thus, the ethnic identity of immigrants and its consequences in Greece are of vital importance. A healthy Greek - as well as a European-immigration system should recognise labour immigration flows and the potential of repeat immigration and evaluate the cornerstone features of ethnic identity. Steadily, the limited European research is showing that assimilation and integration result in positive economic outcomes, but information from the constituent member states is valuable for a complete picture so that policy changes can take place. 
Several factors demonstrate the importance of this study and its contribution to understand how immigrant wages are affected by ethnic identity patterns in Greece. Despite its strengths, most studies have weaknesses that limit the generalisability of the findings, and this study is no exception. Thus, the findings have to be interpreted in light of the limitations that are associated with this study. The current findings are strictly applicable only to the time, place, immigrant groups, employee demographic, and social and labour characteristics from which the sample was drawn. In addition, the current data are cross-sectional, making difficult to draw conclusions only on the associations but not the causes. Note also that, although the model proposed by Berry (1980) has been widely accepted and has yielded a number of studies that have promoted the understanding of acculturation, the model has received criticism on methodological and ideological grounds. Indeed, research suggests that more empirically rigorous ways of classifying individuals (e.g., cluster analysis, latent class analysis) may not extract all of the categories, or may extract multiple variants of one or more of the categories (Schwartz and Zamboanga, 2008). This would seem to suggest that not all of Berry's (1980) categories may exist in a given sample or population, and that some categories may have multiple subtypes. For instance, Sayegh and Lasry (1993) provided a comprehensive and cohesive assessment of the various bidimensional models and measurements of acculturation. Unfortunately, however, in the current study we do not have valuable information based on other major acculturation scales to make comparisons. Moreover, although migrants likely are at choice regarding some aspects of their acculturation, other aspects are constrained by demographic or contextual factors. As Chirkov (2009) suggests a more nuanced approach, based on Berry's (1980) model but adjusting for the many variations among migrants and among 
their circumstances, may have more explanatory power and broader applicability compared to a 'one size fits all' perspective.

\section{Conclusion}

Utilizing the Greek Migration Study (2009-2010), the current study has investigated the effect of Albanian, Bulgarian, Romanian, Georgian, and Russian immigrants' ethnic identities on wages during the residence of these groups in Greece. This study operationalises ethnic identity by establishing five groups of essential elements (language, cultural elements, self-identification, societal interaction, and future citizenship plans) that can best capture the features of ethnic identity. Following Berry's $(1980 ; 1997)$ theory of ethnic identity and using these factor groups, the methodology distinguished between assimilation, integration, separation and marginalisation. The estimations suggest that wage level is positively associated with integration and assimilation and negatively associated with separation and marginalisation. Meanwhile, the results indicated dramatic wage growth for fully integrated or assimilated immigrants and vast wage losses for totally separated or marginalised immigrants. The study concludes that immigrants who are culturally well adjusted to the host society are likely to be economically better off than immigrants who remain strongly attached to their own culture. The current research adds to the limited European studies, which come mainly from Spain (Izquierdo et al, 2009), England (Battu and Zenou, 2010; Manning and Roy, 2010) and Germany (Constant and Zimmermann, 2008; Casey and Dustmann, 2010) and evaluate positive patterns between immigrants' identification with the host country and their economic outcomes. 


\section{References}

Akerlof, G. A. Kranton, R. E. (2000). Economics and Identity. Quarterly Journal of Economics, 115:715-753.

Aldashev, A. Gernandt, J and Thomsen, S. (2009). Language Usage. Participation, Employment and Earnings. Evidence for Foreigners in West Germany with Multiple Sources of Selection. Labour Economics, 16:330-341.

Algan, Y. Dustmann, C. Glitz, A. and Manning, A. (2010). The Economic Situation of First and Second-Generation Immigrants in France, Germany and the United Kingdom. The Economic Journal, 120:4-30.

Baldwin, L. M. And Johnson, W. G. (2000). Labour Market Discrimination Against Men with disabilities in the year of the ADA. Southern Economic Journal, 66:548-566.

Balourdos, D. (2009). The Employment of Skilled Immigrants: Can Greece Adopt a More Selective Policy? Mutual Learning Programme, DG Employment and Social Affairs, Peer Review on Renewed Procedures for Employing Migrant Workers with the Emphasis on Favouring Highly-Qualified Labour. Estonia, 11th and 12th June 2009. 
Balourdos, D. (2010). Greece: Mutual Learning Programme, DG Employment and Social Affairs, Peer Review on Making a Success of Integrating Immigrants into the Labour Market. Norway, 18-19 November 2010.

Battu, H. and M. Zenou, V. (2010). Oppositional Identities and Employment for Ethnic Minorities: Evidence from England. The Economic Journal, 120:52-71.

Berry, J. W. (1980). Acculturation as Varieties of Adaptation, in Padilla, A. M. (Ed.). Acculturation: Theory, Models and Some New Findings. Westview, Boulder, CO.

Berry, J. W. and Sam, D. (1997). Acculturation and Adaptation, in Berry, J. W. Segall, M. H. and Kagitcibasi, C. (Eds.). Handbook of Cross-Cultural Psychology, Social Behavior and Applications. Boston: Allyn and Bacon.

Berry, J. W. (2006). Contexts of Acculturation, In Sam, D. L. and Berry, J. W. (Eds.). Cambridge Handbook of Acculturation Psychology. New York: Cambridge University Press.

Borjas, G. (1985). Assimilation, Changes in Cohort Quality and the Earnings of Immigrants. Journal of Labor Economics, 3:463-489.

Borjas, G. Bronars, S. Trejo, S. (1992). Assimilation and the Earnings of Young Internal Migrants. The Review of Economics and Statistics, 74:170-175. 
Broersma, F and Lazarescu, D. (2009). Pakistani and Bangladeshi Migration to Greece: Chasing the Dream. European Commission: Brussels.

Casey, T. and Dustmann, C. (2010). Immigrants' Identity, Economic Outcomes and the Transmission of Identity Across Generations. The Economic Journal, 120:31-51.

Chirkov, V. (2009). Summary of the Criticisms and of the Potential Ways to Improve Acculturation Psychology. International Journal of Intercultural Relations, 33:177-180.

Chiswick, B. R. (1978). The Effect of Americanization on the Earnings of Foreign-Born Men. Journal of Political Economy, 86:897-921.

Chiswick, B. R., Cohen, Y. and Zach, T. (1997). The Labour Market Status of Immigrants Effects of the Unemployment Rate at Arrival and Duration of Residents. Industrial and Labour Relations Review, 50:289-303.

Chiswick, B. R. and Miller, P. W. (1998). English Language, Fluency Among Immigrants in the Unites States. Research in Labour Economics, 17:151-170.

Cholezas, I. and Tsakloglou, P. (2009). The Economic Impact of Immigration in Greece: Taking Stock of the Existing Evidence. Southern European and Black Sea Studies, 9:77-104. 
Constant, A. and Zimmermann, K. (2008). Measuring Ethnic Identity and Its Impact on Economic Behavior. Journal of the European Economic Association, 6:424-433.

Constant, A. F. Gataullina, L. and Zimmermann, K. F. (2009a). Ethnosizing Immigrants. Journal of Economic Behavior and Organization, 69:274-287.

Constant, A. F. Rowan, R. and Zimmermann, K. F. (2009b). Ethnic Identity and Immigrant Homeownership. Urban Studies, 46: 1879-1898.

Cutler, D. M. (1997). Are Ghettos Good Or Bad? Quarterly Journal of Economics, 112:827-872.

Dancygier, R. M. (2010). Immigration and Conflict in Europe. Cambridge University Press.

Demoussis, M. Giannakopoulos, N. and Zografakis, S. (2010). Native-Immigrant Wage Differentials and Occupational Segregation in the Greek Labour Market. Applied Economics, 42:1015-1027.

del Pilar, J. A. and Udasco, J. O. (2004). Deculturation: Its Lack of Validity. Cultural Diversity and Ethnic Minority Psychology, 10:169-176.

Dickerson, N. T. Johnson, J. (2010) Latino Employment and Residential Segregation in Metropolitan Labor Markets. Du Bois Review: Social Science Research on Race, $7: 151-184$ 
Drydakis N. and Vlassis, M. (2010). Ethnic Discrimination in the Greek Labour Market: Occupational Access, Insurance Coverage, and Wage Offers. Manchester School, 78:201-218.

Drydakis N. (2011). Ethnic Discrimination in the Greek Housing Market. Journal of Population Economics, 24(4):1235-1255.

Drydakis N. (2010a). Ethnic Differences in Housing Opportunities. Urban Studies, 47: 2573-2596.

Drydakis, N. (2010d). Health-Impairments and Labour Market Outcomes. European Journal of Health Economics, 11: 457-469.

Drydakis, N. (2010c). Religious Affiliation and Labour Bias. Journal for the Scientific Study of Religion, 49: 472-488.

Epstein, J. A. Botvin, G. J. and Diaz, T. (1998). Linguistic Acculturation and Gender Effects on Smoking Among Hispanic Youth. Preventive Medicine, 27:583-589.

Fairchild, G. (2009). Racial Segregation in the Public Schools and Adult Labor Market Outcomes: The Case of Black Americans. Small Business Economics, 33: 467484 
Fakiolas, R. (2003). Regularising Undocumented Immigrants in Greece: Procedures and Effects. Journal of Ethnic and Migration Studies, 29(3): 535-561.

Gropas, R. and Triandafyllidou, A. (2005). Migration in Greece at a Glance. Athens, Hellenic Foundation for European and Foreign Policy.

Hausman, J. (1978). Specification Test in Econometrics. Econometrica, 46:1251-1271.

Hausman, J. (2001). Mismeasured Variables in Econometric analysis: Problem form the Right and From the Left. Journal of Economics Perspectives, 15:57-67.

Heckman, J. (1974). Shadow Prices, Market Wages and Labour Supply. Econometrica, 42: 679-694.

Izquierdo, M. Lacuesta, A. and Vegas, R. (2009). Assimilation of Immigrants in Spain: A Longitudinal Analysis. Labour Economics, 16:669-678.

Kontis, A. Zografakis, S. and Mitrakos, Th. (2006). The Economic Impact of Employing Immigrants During the Last Decade in GDP. Athens, Hellenic Migration Policy Institute.

Laroche, M. Kim, Ch. Tomic, M. Belisle, D. (2005). Similarities in Italian and Greek Multidimensional Ethnic Identity some Implications for Food Consumption. Canadian Journal of Administrative Sciences, 22:143-167. 
Maroukis, T. and Triandafyllidou, A. (2008). Violent Radicalization and Strategies for Prevention: Muslim immigrants in Greece. The Change Institute, London, United Kingdom.

Manning, A. and Roy, S. (2010). Culture Clash or Culture Club? The Identity and Attitudes of Immigrants in Britain. The Economic Journal, 120:72-100.

Massey, D. and Denton, N. A. (1993). American Apartheid: Segregation and the Making of the Underclass. Cambridge, MA: Harvard University Press.

Mason, P. L. (2004). Annual Income, Hourly Wages, and Identity among MexicanAmericans and Other Latinos. Industrial Relations, 43:817-834.

Mincer, J. (1974). Schooling, Experience, and Earnings. New York: National Bureau of Economic Research.

Ministry of Interior. Law 2010/3833. Current Provisions for Greek Citizenship and the Political Participation of Foreign-Born Greeks and of Legally Residing Immigrants. Greece.

Montgomery, G. (1992). Comfort with Acculturation Status among Students from South Texas. Hispanic Journal of Behavioral Sciences, 14:201-223. 
Nguyen, H. H. von Eye, A. (2002). Validating an Acculturation Scale for Vietnamese Adolescents (ASVA) a Bidimensional Perspective. International Journal for Behavioral Development, 26: 202-213.

Ogden, D. Ogden, J. Schau, H. (2004). Exploring the Impact of Culture and Acculturation on Consumer Purchase Decisions Towards a Microcultural Perspective. Academy of Marketing Science Review.

Oreopoulos, P. (2003). The Long-Run Consequences of Living in a Poor Neighborhood. Quarterly Journal of Economics, 118:1533-1575.

Phinney, J. (1992). The Multi-group Ethnic Identity Measure: A New Scale for Use with Diverse Groups. Journal of Adolescent Research, 7:156-176.

Phinney, J. Horenczyk, G. Liebkind, K. and Vedder, P. (2001). Ethnic Identity, Immigration, and Well-Being. An International Perspective. Journal of Social Issues, 57:493-510.

Ruble, B. (1989). Ethnicity and Soviet Cities. Soviet Studies, 41:401-414.

Sayegh, L. and Lasry, J. (1993). Acculturation, Stress and Mental Health Among Lebanese Immigrants in Montreal. Sante Mentale Au Quebec, 18:23-52. 
Schwartz, S. J. and Zamboanga, B. L. (2008). Testing Berry's Model of Acculturation: A Confirmatory Latent Class Approach. Cultural Diversity and Ethnic Minority Psychology, 14:275-285.

Schwartz, S. J. Unger, B. J. Zamboanga, B. L. and Szapocznik, J. (2010). Rethinking the Concept of Acculturation: Implications for Theory and Research. American Psychologist, 65:237-251.

Selod, H. and Zenou, Y. (2006). City-Structure, Job Search, and Labour Discrimination. Theory and Policy Implication. The Economic Journal, 116:1057-1087.

Simopoulos, Ch. (2005). The Relationship of Immigrants with Administration. In Migration Policy and Immigrants’ Rights. Labour Institute Study, Athens.

Unger, J. Gallaher, P. Shakib, S. Ritt-Olson, A. Palmer, P. Johnson, C. (2002). The AHISMA Acculturation Scale a New Measure of Acculturation for Adolescents in a Multicultural Society. Journal of Early Adolescence, 23:225-251.

Xie, M. (2010). The Effects of Multiple Dimensions of Residential Segregation on Black and Hispanic Homicide Victimization. Journal of Quantitative Criminology $26: 237-268$. 
Table 1. Measuring immigrants' ethnic identity

\begin{abstract}
A. Which one of the following four best describes your language usage:
[1] A strong identification with the Greek language coupled with a weak identification to the language of your country of origin

[2] Combination of strong identification with the Greek language and strong identification with the language of your country of origin

[3] An exclusive commitment to your original language paired with weak involvement with Greek language

[4] A weak dedication to or strong detachment from either Greek or your original language

B. Which one of the following four best describes your cultural habits:

[1] A strong identification with the Greek food, media, music and reading coupled with a weak identification to the food, media, music and reading of your country of origin

[2] Combination of strong identification with the Greek food, media, music and reading and strong identification with the food, media, music and reading of your country of origin

[3] An exclusive commitment to the food, media, music and reading associated with your country of origin paired with weak involvement with Greek food, media, music and reading

[4] A weak dedication to or strong detachment from either Greek or the food, media, music and reading of your country of origin
\end{abstract}

C. Which one of the following four best describes your ethnic self-identification:

[1] A strong identification with the Greek identification coupled with a weak identification with your country of origin identification

[2] Combination of strong identification with the Greek identification, and strong identification with your country of origin identification

[3] An exclusive commitment to your country of origin identification, paired with weak involvement with Greek identification

[4] A weak dedication to or strong detachment from either Greek or your country of origin identification

D. Which one of the following four best describes your ethnic networks:

[1] A strong close-friendship with Greeks coupled with a weak close-friendship with people of your country of origin

[2] Combination of strong close-friendship with Greeks, and strong identification with close-friendship with people of your country of origin

[3] An exclusive commitment to your country of origin close-friendship, paired with weak involvement with Greeks as close-friends

[4] A weak dedication to or strong detachment from either Greek or your country of origin close-friendship

E. Which one of the following four best describes your future citizenship plans:

[1] A strong identification with Greek citizenship and residency plans with a weak identification to citizenship and residency plans of your country of origin

[2] Combination of both Greek citizenship and residency plans, and strong identification with citizenship and residency plans of your country of origin

[3] An exclusive commitment to your country of origin citizenship and residency plans, paired with weak involvement with Greek citizenship and residency plans

[4] A weak dedication to or strong detachment from either Greek or citizenship and residency plans of your country of origin

Note. Option [1] corresponds to assimilation, option [2] corresponds to integration, option [3] corresponds to separation, and option [4] corresponds to marginalisation. Question B, which measures immigrants' cultural habits, is the average of four elements: food, media, music and reading preferences. In the real ethnic identity scale questionnaires, respondents had to response separately for each cultural habit. 
Table 2. Definitions of variables

\begin{tabular}{|c|c|}
\hline $\begin{array}{l}\text { Variable } \\
\text { Name }\end{array}$ & Definition \\
\hline HW & Natural logarithm of hourly wages \\
\hline AS & Assimilation index \\
\hline IN & Integration index \\
\hline SE & Separation index \\
\hline MA & Marginalization index \\
\hline LF & The number of labour force \\
\hline EM & The number of employed individuals \\
\hline $\mathrm{UN}$ & The number of unemployed individuals \\
\hline NP & The number of non-participant in the labour force (non-employed) \\
\hline ALB & 1 if individual is from Albania; 0 otherwise \\
\hline BUL & 1 if individual is from Bulgaria; 0 otherwise \\
\hline GEO & 1 if individual is from Georgia; 0 otherwise \\
\hline ROM & 1 if individual is from Romania; 0 otherwise \\
\hline RUS & 1 if individual is from Russia; 0 otherwise \\
\hline AGE & Years of age \\
\hline SEX & 1 if individual is male; 0 otherwise \\
\hline MARR & 1 if individual is married; 0 otherwise \\
\hline CHIL & Number of children in household \\
\hline MIG & Years since immigration in Greece \\
\hline CHR & 1 if the individual is Christian; 0 otherwise \\
\hline DIS & $\begin{array}{l}1 \text { if individual is limited in kind or amount of work, has a mobility limitation, or has a personal care } \\
\text { limitation; } 0 \text { otherwise }\end{array}$ \\
\hline SCHOL & 1 if individual has completed minimum mandatory education; 0 otherwise \\
\hline GRAD & 1 if individual has graduated from a high school; 0 otherwise \\
\hline UNIV & 1 if individual has university or a technical school diploma; 0 otherwise \\
\hline SCHOLH & 1 if individual has completed minimum mandatory education in her/his home country; 0 otherwise \\
\hline GRADH & 1 if individual has graduated from a high school from her/his home country; 0 otherwise \\
\hline UNIVH & 1 if individual has university or a technical school diploma from her/his home country; 0 otherwise \\
\hline $\mathrm{PC}$ & 1 if individual has computer skills; 0 otherwise \\
\hline ENGL & 1 if individual has knowledge of English; 0 otherwise \\
\hline EXPER & Years of actual working experience \\
\hline EXPERH & Years of actual working experience from individual's home country \\
\hline EXPERG & Years of actual working experience from Greece \\
\hline WHITE & $\begin{array}{l}1 \text { if individual's occupation is among managerial or professional specialties, or the individual works } \\
\text { in a technical, sales, or administrative support position; } 0 \text { otherwise }\end{array}$ \\
\hline BLUE & $\begin{array}{l}1 \text { if individual's occupation is among precision production, craft, or repair occupations, or the } \\
\text { individuals works as an operator, fabricator or labourer; } 0 \text { otherwise }\end{array}$ \\
\hline SERV & $\begin{array}{l}1 \text { if individual is in a service occupation (i.e. food preparation, protective service occupation, } \\
\text { ground cleaning and maintenance occupations, personal care and healthcare support occupations); } 0 \\
\text { otherwise }\end{array}$ \\
\hline PUBL & $\begin{array}{l}1 \text { if individual is employed in the public sector; } 0 \text { if individual is employed in the private sector } \\
\text { (PRIV; reference group) }\end{array}$ \\
\hline PART & 1 if individual is a part time employee, 0 otherwise (i.e. full time employee; FULL) \\
\hline LC & City controls \\
\hline
\end{tabular}




\begin{tabular}{|c|c|c|}
\hline & Mean & $\begin{array}{l}\text { Standard } \\
\text { Deviation }\end{array}$ \\
\hline Number of observations (employed + unemployed + non participants) & 1,837 & \\
\hline Percentage of labour force (employed + unemployed) & $77.53 \%$ & 0.41 \\
\hline Percentage of employed individuals (labour force - unemployed) & $85.30 \%$ & 0.35 \\
\hline Percentage of Albanians & $36.15 \%$ & 0.48 \\
\hline Percentage of Bulgarians & $12.51 \%$ & 0.33 \\
\hline Percentage of Georgians & $12.24 \%$ & 0.32 \\
\hline Percentage of Romanians & $18.65 \%$ & 0.38 \\
\hline Percentage of Russians & $20.45 \%$ & 0.40 \\
\hline Hourly wage in Euros & 4.15 & 1.24 \\
\hline - Wage in white collar jobs & 4.67 & 1.49 \\
\hline - Wage in blue collar jobs & 3.89 & 0.99 \\
\hline - Wage in service jobs & 4.06 & 1.25 \\
\hline - Wage in public jobs & 4.71 & 1.30 \\
\hline - Wage in private jobs & 4.10 & 1.18 \\
\hline Mean value of integration index & 1.45 & 0.54 \\
\hline Mean value of assimilation index & 1.10 & 1.04 \\
\hline Mean value of separation index & 1.90 & 0.91 \\
\hline Mean value of marginalization index & 0.54 & 0.55 \\
\hline Mean age & 36.95 & 6.02 \\
\hline Percentage of males & $37.29 \%$ & 0.48 \\
\hline Percentage who are married & $52.23 \%$ & 0.49 \\
\hline Mean number of children in household & 0.56 & 0.89 \\
\hline Mean number of immigration years in Greece & 15.43 & 4.74 \\
\hline Percentage of Christians & $62.05 \%$ & 0.48 \\
\hline Percentage with disability limitations & $10.68 \%$ & 0.30 \\
\hline Percentage completing minimum mandatory education & $75.79 \%$ & 0.42 \\
\hline Percentage of high school graduates & $64.55 \%$ & 0.47 \\
\hline Percentage of university or technical school graduates & $17.21 \%$ & 0.37 \\
\hline Percentage completing minimum mandatory education in home country & $96.76 \%$ & 0.17 \\
\hline Percentage of high school graduates in home country & $92.48 \%$ & 0.26 \\
\hline Percentage of university or technical school graduates in home country & $77.07 \%$ & 0.42 \\
\hline Percentage with computing skills & $19.73 \%$ & 0.39 \\
\hline Percentage with English skills & $25.24 \%$ & 0.43 \\
\hline Mean years of actual working experience & $18.08 \%$ & 5.70 \\
\hline Mean years of actual working experience in Greece & $14.40 \%$ & 4.29 \\
\hline Percentage in white-collar jobs & $3.38 \%$ & 0.18 \\
\hline Percentage in blue-collar jobs & $72.38 \%$ & 0.44 \\
\hline Percentage in service occupations & $24.24 \%$ & 0.42 \\
\hline Percentage in public sector & $7.01 \%$ & 0.25 \\
\hline Percentage of part-time work & $2.00 \%$ & 0.12 \\
\hline Percentage living in the capital of Greece (Athens) & $38.13 \%$ & 0.29 \\
\hline
\end{tabular}
Notes: Data Source, Greek Migration Study (2009-2010). 
Table 4. Coefficients from wage regression

\begin{tabular}{|c|c|}
\hline Assimilation & $0.184(0.005)^{*}$ \\
\hline Integration & $0.159(0.015)^{*}$ \\
\hline Separation & $-0.205(0.006)^{*}$ \\
\hline Marginalization & $-0.283(0.014)^{*}$ \\
\hline Bulgarians & $-0.035(0.006)^{*}$ \\
\hline Georgians & $-0.047(0.009)^{*}$ \\
\hline Romanians & $-0.052(0.011)^{*}$ \\
\hline Russians & $0.025(0.014)^{* * *}$ \\
\hline Age & $0.063(0.012)^{*}$ \\
\hline $\mathrm{Age}^{2}$ & $-0.0006(0.000)^{*}$ \\
\hline Men & $0.118(0.006)^{*}$ \\
\hline Married & $0.022(0.014)$ \\
\hline Number of children & $0.017(0.011)$ \\
\hline Years of immigration in Greece & $0.138(0.003)^{*}$ \\
\hline Christians & $0.027(0.048)$ \\
\hline Disability status & $-0.093(0.006)^{*}$ \\
\hline Graduation from high school & $0.057(0.005)^{*}$ \\
\hline University or technical school diploma & $0.064(0.004)^{*}$ \\
\hline Graduation from high school in home country & $0.031(0.036)$ \\
\hline $\begin{array}{l}\text { University or technical school diploma in home } \\
\text { country }\end{array}$ & $0.079(0.003)^{*}$ \\
\hline Knowledge of computer & $0.008(0.013)$ \\
\hline Knowledge of English & $0.015(0.011)$ \\
\hline Actual work experience & $0.025(0.003)^{*}$ \\
\hline Actual work experience in home country & $0.012(0.055)$ \\
\hline Actual work experience in Greece & $0.030(0.004)^{*}$ \\
\hline White collar jobs & $0.112(0.005)^{*}$ \\
\hline Blue collar jobs & $-0.097(0.052) * * *$ \\
\hline Public sector & $0.202(0.015)^{*}$ \\
\hline Full time employment & $0.261(0.006)^{*}$ \\
\hline City controls & yes \\
\hline Intercept & $1.502(0.114)^{*}$ \\
\hline $\operatorname{Adj} R^{2^{2}}$ & 0.640 \\
\hline Observations & 1,213 \\
\hline
\end{tabular}

Notes: Data Source, Greek Migration Study (2009-2010). Standard errors are in parenthesis. *Significant at the $1 \%$ level. *** Significant at the 10\% level. 
Table 5. Coefficients from wage regression per ethnic group

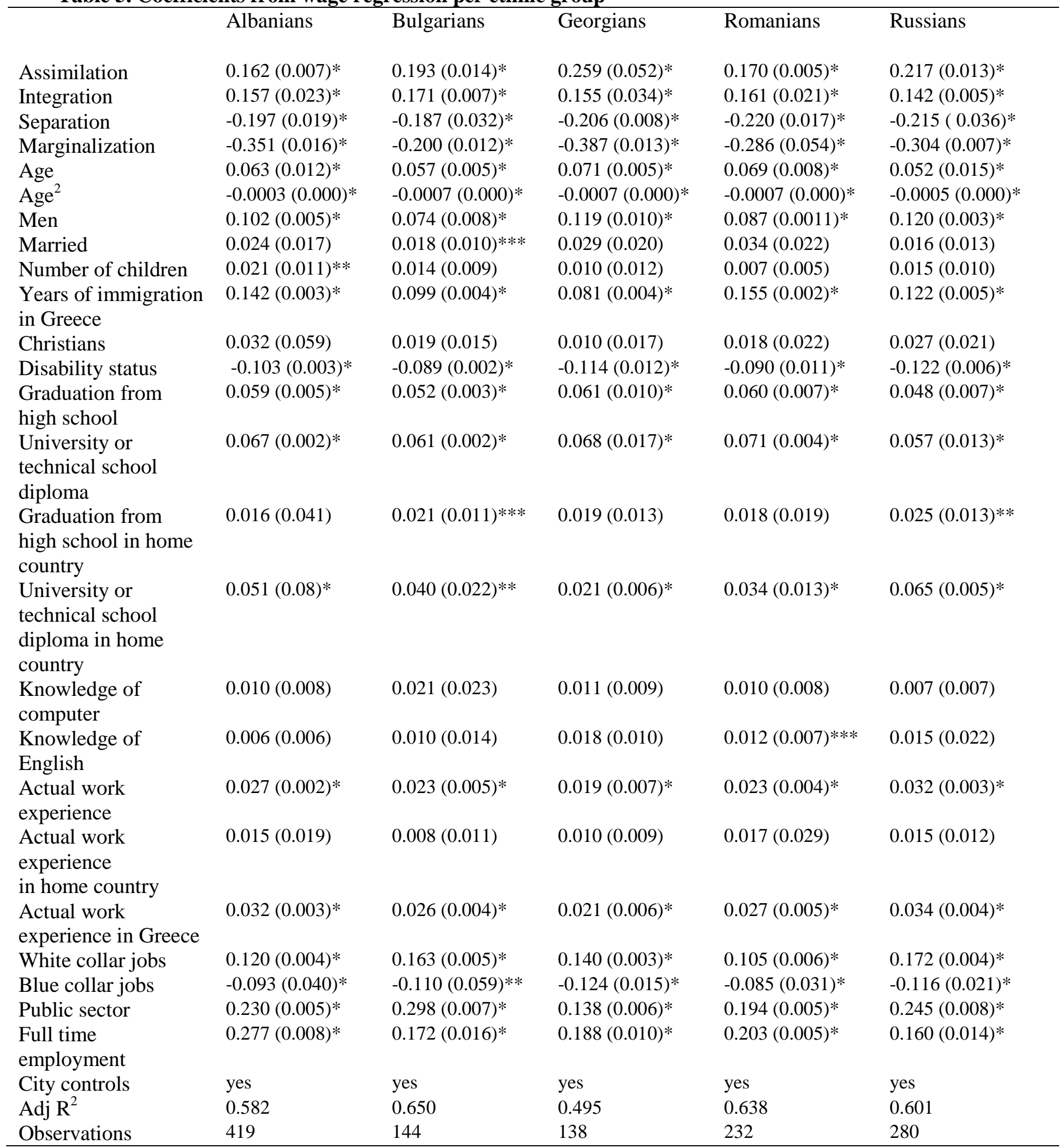

Notes: Data Source, Greek Migration Study (2009-2010).Each column is a separate regression. Standard errors are in parenthesis. * Significant at the $1 \%$ level. ** Significant at the 5\% level. *** Significant at the $10 \%$ level. 
Table 6. Variations in hourly wages per ethnic group and ethnic identity

\begin{tabular}{lllllll}
\hline & Total & Albanians & Bulgarians & Georgians & Romanians & Russians \\
& & & & & & \\
Assimilation & 19.15 & 16.70 & 20.67 & 30.58 & 17.39 & 20.76 \\
Integration & 8.72 & 8.82 & 9.79 & 8.38 & 8.51 & 7.45 \\
Separation & -18.81 & -17.92 & -16.30 & -23.58 & -19.44 & -17.35 \\
Marginalization & -15.79 & -18.84 & -10.96 & -19.20 & -16.04 & -17.99 \\
\hline
\end{tabular}

Notes: Data Source, Greek Migration Study (2009-2010). Each cell is a separate calculation. 
Table 7. Variations in monthly wages per ethnic group and ethnic identity

\begin{tabular}{lllllll}
\hline & Total & Albanians & Bulgarians & Georgians & Romanians & Russians \\
& & & & & & \\
Assimilation & 119.15 & 116.70 & 120.67 & 130.58 & 117.39 & 120.76 \\
Integration & 108.72 & 108.82 & 109.79 & 108.38 & 108.51 & 107.45 \\
Separation & -81.19 & -82.02 & -83.70 & -76.42 & -80.56 & -82.65 \\
Marginalization & -84.21 & -81.16 & -89.04 & -80.80 & -83.96 & -82.01 \\
\hline
\end{tabular}

Notes: Data Source, Greek Migration Study (2009-2010). Each cell is a separate calculation. 


\section{Endnotes}

${ }^{\mathrm{i}}$ Research contributions on the significance of immigrants' ethnic diversity share an understanding of ethnic identity to denote the balance between commitment to, affinity with, or self-identification with the culture, norms, and society of origin and commitment to or self-identification with the host culture and society (Berry, 1980; Ruble, 1989; Schwartz et al, 2010).

${ }^{\text {ii }}$ Similarly, all over Europe (e.g., Britain, Denmark, France, Germany), as well as in the United States and Australia, identity is a new facet of immigration policy and minorityrelated issues (for a discussion see, Casey and Dustmann, 2010).

iii The main challenges facing Greek immigration policy were as follows: first, how to effectively control immigrant inflows; second, how to prevent legal immigrants from lapsing into illegality; and third, how to help promote immigrants' economic and social integration (Fakiolas, 2003; Simopoulos, 2005).

${ }^{\text {iv }}$ More recent immigrant groups consist of Asian nationalities, especially Pakistani and Bangladeshi, and political asylum and/or illegal migration flows through Turkey of Afghans, Iranians, Iraqis, Somalians and others (see Broersma and Lazarescu, 2009). Most recently, increases in such flows have led to the emergence of immigration as a political issue.

\footnotetext{
${ }^{v}$ As documented in the Greek literature, immigrants have an impact on the growth and development of the country. The value of various ethnicities is evidenced in Greek cities
} 
through the increase in the Gross Domestic Product growth rate, the revitalization of the agricultural sector, the establishment of many small and medium-sized enterprises, at least in the short term, and the dampening of inflationary pressures. Cholezas and Tsakloglou (2009) suggest that, in sum, most studies agree that immigration in Greece has had positive and negative economic effects. Most probably, the authors conclude, the positive outweigh the negative effects.

${ }^{\mathrm{vi}}$ As Balourdos (2009) evaluates immigrants have been concentrated in the low skilled jobs, in traditional sectors of the economy such as building and construction, personal services, wholesale and retail trade, hotels and restaurants. The majority of immigrant workers were willing to accept atypical and precarious employment, the so called '3D'jobs' (dirty, dangerous and demanding work) in the secondary labour market, which are low paid and rejected by the domestic labour force.

${ }^{\text {vii }}$ Constant and Zimmermann (2008), Constant et al (2009a) and Constant et al (2009b) call this measure 'ethnosizer'.

viii Immigrants arrive in a new country with differing attitudes about retaining their cultures of origin and becoming part of the new society. In the new society, however, these attitudes interact with the actual and perceived levels of acceptance of immigrants and with official policies toward immigration (Montgomery 1992; Phinney et al, 2001; Unger et al, 2002; Nguyen and von Eye, 2002). Ethnic identity is likely to be strong when immigrants have a strong desire to retain their identities, when pluralism is encouraged or when immigrant groups feel accepted. However, some immigrants may 
downplay or reject their own ethnic identities in the face of real or perceived hostility toward them or toward particular groups. Other immigrant groups may assert pride in their cultural group and emphasise solidarity as a way of dealing with negative attitudes. As Berry (1997) and Berry and Sam (1997) suggest, the relationship will be influenced by the interaction of the characteristics of specific immigrants groups with those of particular setting. As Constant and Zimmermann (2008) point out, ethnic identity is like a property that a person can have for some time, can lose and acquire anew, or can lose and never assume another one.

${ }^{\text {ix }}$ Health impairment-based wage discrimination is a significant problem for Greece (Drydakis, 2010b).

${ }^{\mathrm{x}}$ Religious bias in the labour market, which affects employment rate and earnings, is also a problem for Greece (Drydakis, 2010c).

${ }^{x i}$ Based on the General Confederation of Greek Workers, for the period 2009-2010, the minimum legal hourly wage for unmarried workers without experience was $4.62 €$. For married workers without experience, the minimum legal wage was 5.08€. In each group, every three additional years of working experience yielded a $0.37 €$ increase in the minimum wage. Actually, Drydakis and Vlassis (2010) confirm an ethnic penalty on immigrants' wages, of approximately $11 \%$.

xii The white-collar sector contains independent and subordinate sectors. White-collar sector occupations usually require specific skills or prior training. It is only in this sector 
that the wages of workers are tied to their productivity. Conversely, the blue-collar sector demands unskilled, rudimentary, menial, repetitive, interchangeable, and substitutable or expendable labour. Schooling and on-the-job training are irrelevant for these workers' wages. The wage profile in this sector is flatter than the earnings profile in the white-collar sector. The main determinant of wages in the blue-collar sector is hours of work.

xiii The validity of marginalization as an approach to acculturation has been questioned (del Pilar and Udasco, 2004). The likelihood that a person will develop a cultural sense of self without drawing on either the heritage or receiving cultural contexts is likely low. The marginalization approach may be viable only for the small segment of migrants who reject (or feel rejected by) both their heritage and receiving cultures (Berry, 2006).

xiv Methodologically, for identification purposes not to solely rely on distributional assumptions, we choose (as in Aldashev et al, 2009) 'marital status' and 'children' as the exclusion restrictions that enter the participation equation, but not the employment equation. In the regression stage, both variables are found to have a statistically significant effect, thereby justifying the choice of exclusion variables. The correlation between the errors of the participation equation and the employment equation was estimated to be statistically insignificant, and therefore, we estimated both equations separately. Finally, the Inverse Mill's ratios turned out to be statistically insignificant. Aldashev et al (2009) works similarly and estimates the same patterns. Under the current framework, sample selection issues are found to have insignificant effects. 
${ }^{x v}$ The preference's equation is identified with a set of appropriate instruments that capture the influence of prior experiences (see also Battu and Zenou, 2010). We choose "whether immigrants have experienced ethnic discrimination in housing", "whether immigrants have experienced ethnic discrimination in occupational access", "whether immigrants have experienced ethnic discrimination in public/private services", and "whether immigrants have experienced verbal harassment by natives" as the extra instrumental variables.

${ }^{x v i}$ Casey and Dustmann (2010) suggest that although ethnic identity and economics outcomes cannot be interpreted as causal; however, it is not implausible that the dominant mechanism leading to biased estimates creates an upward bias, which allows interpretation of estimates as bounds. If for instance, immigrants who are economically successful in Greece develop at the same time a stronger sense of identity with Greece, then we should expect any estimate of our identity measure with Greece, to be upward biased. Following this line of argument, Casey and Dustmann (2010) further suggest that, we may interpret the coefficient estimates as an upper bound (or lower bound in the case of home country identity) of any effect of identity on economic outcomes.

${ }^{x v i i}$ Balourdos (2009) suggests that it is difficult to support that there are serious needs for skilled or highly skilled third country immigrants in Greece. On the contrary, Greece is faced with high unemployment rates and highly skilled native workforce. Although the existing legislative framework facilitates the entry and stay of certain types of skilled or highly skilled immigrants, whenever such a demand is expressed, their 
percentage contribution to total immigrant and overall employment is insignificant (Balourdos, 2009). 